\title{
Failure analysis and structure optimization of ABS coat hanger die Jun Wang ${ }^{1, a}$, Hehui Wang ${ }^{1, b}$, Wenmin $\mathrm{Zhu}^{1}$, Pangu $\mathrm{Lu}^{2}$ \\ ${ }^{1}$ East China University of Science and Technology, Shanghai 200237, China \\ ${ }^{2}$ Gaoqiao Petro-chamical Company, Shanghai 201208, China \\ awangjun513x@163.com, bhhwang@ecust.edu.cn
}

Keywords: Hanger die, Failure analysis, Structure optimization, ICEM; Polyflow, Pressure drop.

\begin{abstract}
In view of the failure of ABS steel extrusion die in a petrochemical enterprise, the finite element software was used to simulate the die runner and the main reason of die failure was that the pressure drop exceeds standard. In this paper, in order to reduce the die pressure drop, improvement schemes are proposed. Firstly, increasing the entrance radius of the manifold can reduce the die pressure drop and the outlet velocity distribution is more uniform. Then, improving the height of sector can significantly reduce the pressure drop but the speed of the export sector becomes more uneven. Through the simulations of the invalid die which key parameters were changed, the rules and trends of the influence the various factors have are obtained quantitatively. This paper provides a reference for the design of the similar coat- hanger die.
\end{abstract}

\section{Introduction}

The coat hanger die is widely used in extrusion of plastic plate, sheet and strip. For the design of the coat hanger die, the pressure drop and the velocity distribution at the outlet of the die are mainly considered.

The coat hanger die design is mainly due to the analytical method and numerical method [1]. There are different theories or criteria [2,3,4] One dimensional analytical method is simple and feasible, and the design equation can be given. However, due to the existence of the ideal assumption, it can't meet the requirements of uniform distribution of exit velocity. With the development of computer technology, it is helpful for analysis of flow channel in the die and structure improvement. Gong et al. [5] verified the coat hanger die design theory by numerical simulation. Zhu Wenmin et al. [6] presented that the increase of the inlet radius of the manifold can obviously reduce the pressure drop of the melt, but it has little effect on the uniform distribution of the outlet velocity. Lee et al. [7] changed the main geometric parameters, flow fan angle and damping zone height and simulated the flow by Polyflow. They found that the sector angle has an obvious influence on the velocity distribution at the exit which decides the quality of the products. While the height of the damping zone has little influence on velocity uniformity at the exit.

The die studied in this article is used to produce ABS steel bar in a chemical enterprise. The die was originally designed by a German company and the design temperature is $260^{\circ} \mathrm{C}$. However, now the process temperature is just $225^{\circ} \mathrm{C}$. If the process temperature is increased, burnt impurities will occur in the ABS products. It doesn't work under 6.9MPa which is the maximum pressure drop provided by equipment. The ABS condensate formed in the mold head is shown in figure 1 . Aiming at the failure of die, we establish the three-dimensional model of the cavity flow by UG. Then we mesh it with ICEM and use Polyflow to do numerical simulation. This paper analyzes what caused the die failure, and studies the influence which the variation of manifold inlet radius and sector thickness has on pressure drop and the velocity uniformity at the exit. Then this paper put forward improvement plans which can give guidance to enterprises on structure optimization of ABS coat hanger die . 


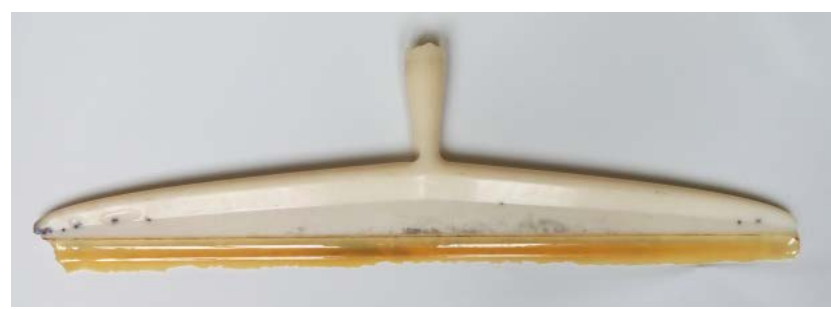

Fig. 1 model of ABS solid state

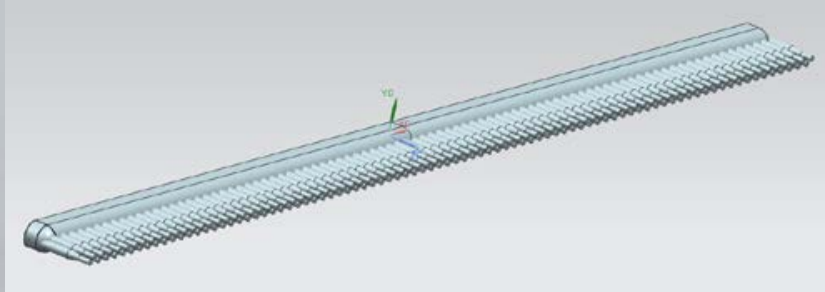

Figure 2 divider formed in the die head (Fig.2)

This paper mainly studies the coat hanger die (Fig.1) and the distributor for the formation of bars

\section{Numerical simulation of die}

\section{Mathematical model.}

According to the specific circumstances of melt delivery, we propose the following assumptions[8],

1) Die cave is filled with melt completely;

2) The melt is incompressible non-Newtonian fluid;

3) Flow field is steady, isothermal and fully developed laminar flow;

4) The inertia and gravity could be neglected;

Based on the above assumption, the continuity equation, the equation of motion, the constitutive equation, the deformation rate tensor under the Cartesian coordinate system could be written as,

$$
\begin{gathered}
\nabla \cdot \boldsymbol{u}=0 \\
-\nabla \cdot p \cdot \boldsymbol{I}+\nabla \cdot \boldsymbol{\tau}=0 \\
\boldsymbol{\tau}=2 \eta \cdot \dot{\gamma} \cdot \boldsymbol{D} \\
\boldsymbol{D}=\left(\nabla \cdot u+\nabla u^{\prime}\right) / 2
\end{gathered}
$$

Where: $\boldsymbol{u}$-speed, $\mathrm{m} / \mathrm{s} ; p$-pressure, Pa; I- unit tensor; $\boldsymbol{\tau}$-stress tensor, Pa; $\dot{\gamma}$ - shear rate, $\mathrm{s}^{-1}$; $\boldsymbol{D}$-deformation rate tensor; $\eta$-apparent viscosity, $\mathrm{Pa} \cdot \mathrm{s}$.

\section{Measurement of material parameters.}

Before the failure analysis of the die, the capillary rheometer was used to measure the rheological data of ABS at various temperatures. The number of ABS is 3504 who's density is $944 \mathrm{~kg} / \mathrm{mm} 3$. The rheological parameters of ABS at $225^{\circ} \mathrm{C}$ were determined by the capillary rheometer RG20 from the Goettfert company in German. The slender ratio is 30:1.

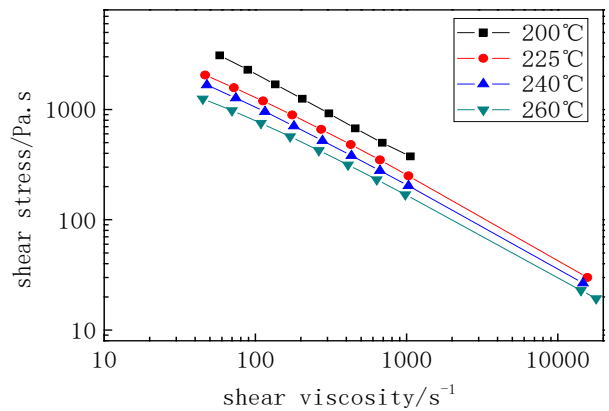

Fig 3 Relationship between shear viscosity and shear rate at different temperatures

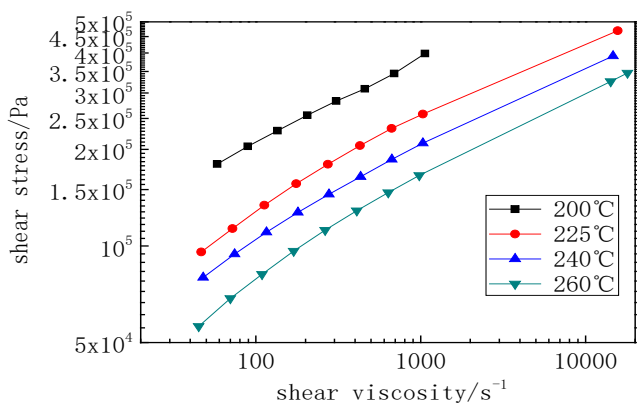

Fig 4 The relationship between shear stress and shear rate at different temperatures

Fig. 3 shows that Relationship between shear viscosity and shear rate at different temperatures. And Fig. 4 shows that the relationship between shear stress and shear rate at different temperatures.

The constitutive model of Polymer.

Bird-Carreau model considers not only the Newton behavior at low shear rate but also the pseudo plastic behavior of high shear rate materials. Bird-Carreau model with four parameters which take both low and high shear rate scope of Newtonian area into account was chosen to describe the relationship between the apparent viscosity and shear rate,

$$
\eta=\eta_{\infty}+\frac{\eta_{0}-\eta_{\infty}}{\left[1+(\lambda \dot{\gamma})^{2}\right]^{\frac{1-n}{2}}}
$$


Where: $\eta_{\infty}$ - infinite-shear-rate viscosity, $\mathrm{Pa} \cdot \mathrm{s}$;

$\eta_{0}$ ZZero-shear-rate viscosity, Pa·s;

$\square \lambda-$ Natural time, s;

$n$-Power law index.

The four parameters in Bird-Carreau model at different temperature obtained by Origin8.0 according to the data measured are reported in table 1.

Table 1 parameters in Bird-Carreau model

\begin{tabular}{|c|c|c|c|}
\hline $\mathrm{T} /{ }^{\circ} \mathrm{C}$ & $\eta_{0}$ & $\lambda$ & $n$ \\
\hline 225 & 10461 & 0.25 & 0.35 \\
\hline 240 & 6453 & 0.15 & 0.33 \\
\hline 260 & 1897 & 0.03 & 0.32 \\
\hline
\end{tabular}

\section{Process parameters and boundary conditions.}

The maximum inlet flow rate of the ABS coat hanger die is $5315 \mathrm{~kg} / \mathrm{h}$. The condition of shear stress on the wall follows the generalized Navier law, and the Navier slip model is established,

$$
\tau_{s}=F_{\text {slip }}\left(u_{\text {wall }}-u_{s}\right)\left|u_{s}-u_{\text {wall }}\right|^{e-1}
$$

Where: $\tau_{\mathrm{s}}$-Shear stress on the wall, Pa; $\mathrm{F}_{\text {slip }}$-Slip coefficient; $\mathrm{u}_{\text {wall }}$-Tangential velocity of melt on

Wall, $\mathrm{m} / \mathrm{s} ; u_{s}$-Tangential velocity of the wall of the die, $\mathrm{m} / \mathrm{s} ; \quad e$-Physical property parameters.

The $e$ in the generalized Navier slip model is equal to the non-Newton index of polymer[9]. Basing on the comparison between the results of the simulation and the contour of pressure drop given by the designer, the $F_{\text {slip }}$ is obtained. The $F_{\text {slip }}$ in this paper is 300000 .

\section{Geometric Model.}

The main work of modeling has two parts, the coat-hanger die and distributor

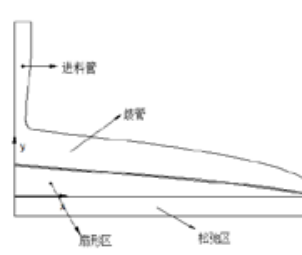

Figure 5 Geometric structure

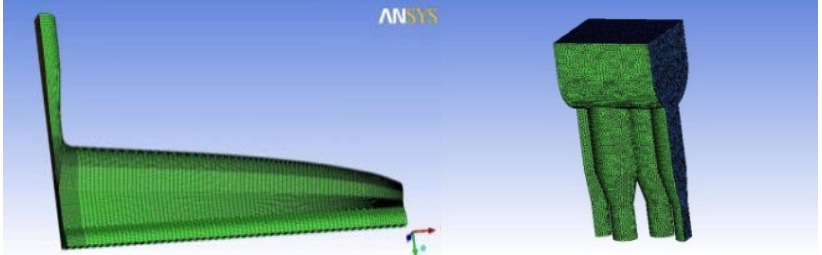

Figure 6 Meshed grid

The coat hanger die is mainly composed of the feed pipe, the manifold, the sector and the relaxation zone(Fig.5). The manifold is a tubular structure with tapered curve. The manifold and the sector ensure the velocity distribution of the melt at the exit should be uniform, which ensure the qualified products. The relaxation zone is to help erase the influence from the historical flow. The three-dimensional model of the coat hanger die was established by UG, and then imported it to ICEM for meshing, hexahedral finite element meshes were obtained with ICEM's powerful O-block function (Fig.6). Considering the symmetry of the hanger die, in order to improve the computational efficiency, just one fourth of the die is considered. The inlet flow rate is $0.369 \mathrm{~kg} / \mathrm{s}$.

There are 174 holes in the distributor with the characteristic of periodic symmetry. The periodic symmetric boundary conditions was used to save the amount of calculation, and can ensure the accuracy of the calculation.Ignoring the influence caused by the ends of distributor, 1/58 of the distributor model was established by UG (Fig.5), and then imported it to ICEM for meshing (Fig.6). The inlet flow rate is $0.0256 \mathrm{~kg} / \mathrm{s}$. 


\section{Results and Analysis}

\section{Analysis of pressure.}

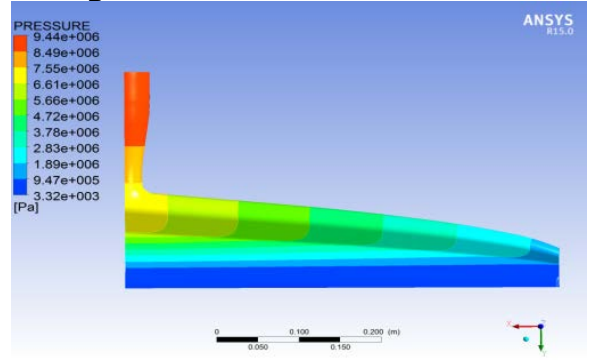

Fig. 7 Pressure distribution of die head

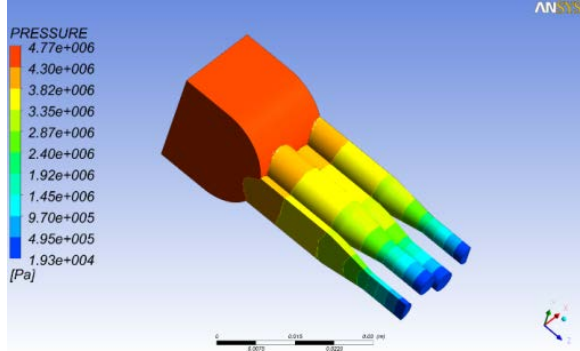

Fig. 8 Pressure distribution of distributor

At present, the actual process temperature in the die cavity is $225^{\circ} \mathrm{C}$. The pressure drop of the die head is $9.44 \mathrm{Mpa}$ which has exceeded 6.9MPa the maximum pressure drop the equipment can provide (Fig.7). The pressure drop is mainly concentrated in the manifold and sector area, and the largest is in the sector area.

\section{Velocity analysis on the outlet.}

Uniform distribution of velocity at the outlet is a key factor for a quality product. Fig.9 and Fig.10 show that there has larger velocity fluctuation on the outlet. The distribution function of the manifold melt is not strong because the velocity at the end of the die is quite low. It can also be found that the velocity distribution at the exit is uneven. The velocity decreases from the symmetry plane to the ends which has a bad influence on the quality of the products.

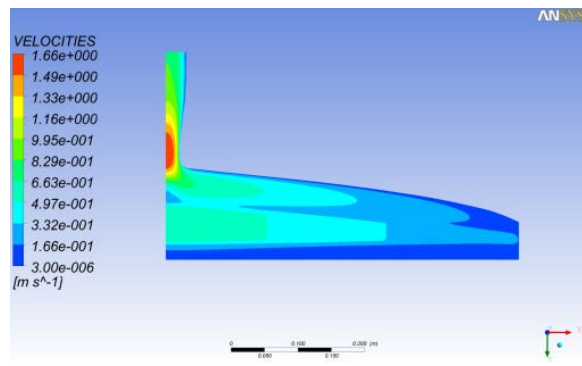

Fig. 9 Velocity distribution on the symmetry plane

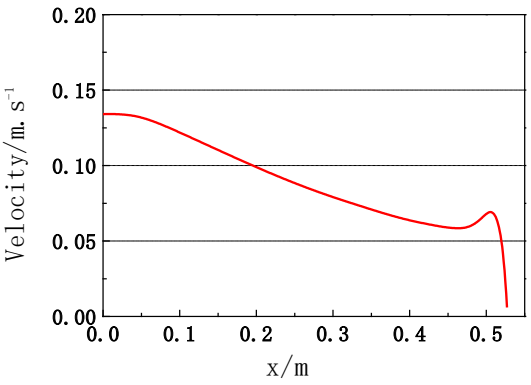

Fig. 10 Velocity at the centerline of the exit

\section{Improvement of hanger die}

In order not to change the size of the product, the improvement schemes are only for the coat-hanger die without change in the distributor.

\section{Improvement schemes.}

The excess of the pressure drop results in the failure of the coat-hanger die. According to the previous studies, it can be seen that the pressure drop at the manifold radius and the fan section are very large. So the die radius and the thickness of the manifold sector was improved, and the pressure field and the velocity field improved were studied.

There are total five improvement schemes in this paper, (a) the radius increases by $3 \mathrm{~mm}$; (b) the radius increases by $5 \mathrm{~mm}$; (c) $\mathrm{H}$ increases to $6 \mathrm{~mm}$; (d) the radius increases by $3 \mathrm{~mm}$ and $\mathrm{H}$ increases to $6 \mathrm{~mm}$; (E) the radius increases by $5 \mathrm{~mm}$ and $\mathrm{H}$ increases to $6 \mathrm{~mm}$. 


\section{Results and analysis.}

\section{1) Analysis of pressure}
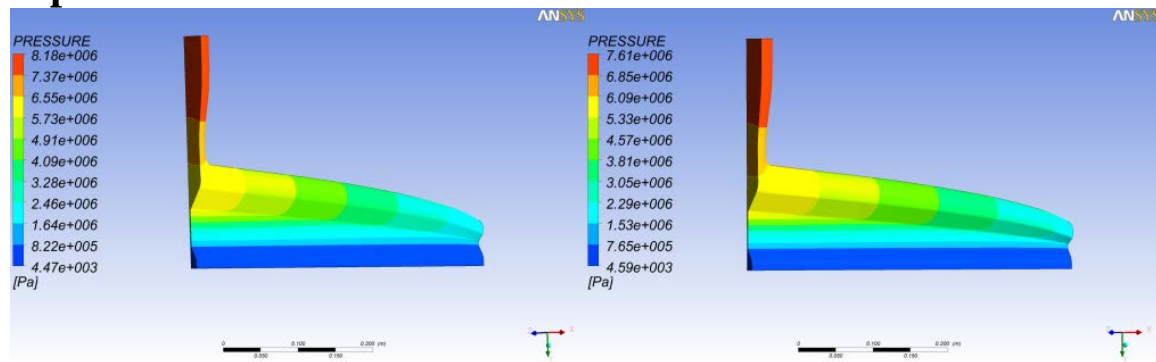

(a) radius increased by $3 \mathrm{~mm}$

(b) radius increased by $5 \mathrm{~mm}$

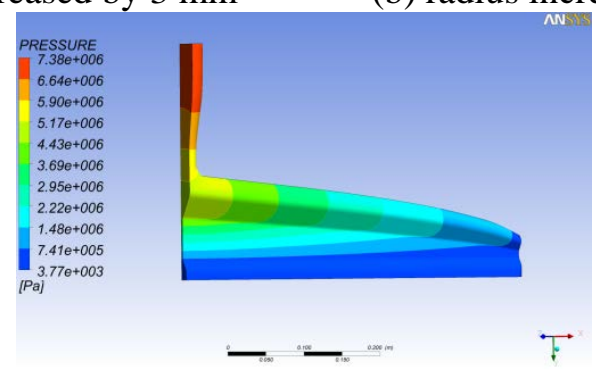

(c) $\mathrm{H}$ increased to $6 \mathrm{~mm}$

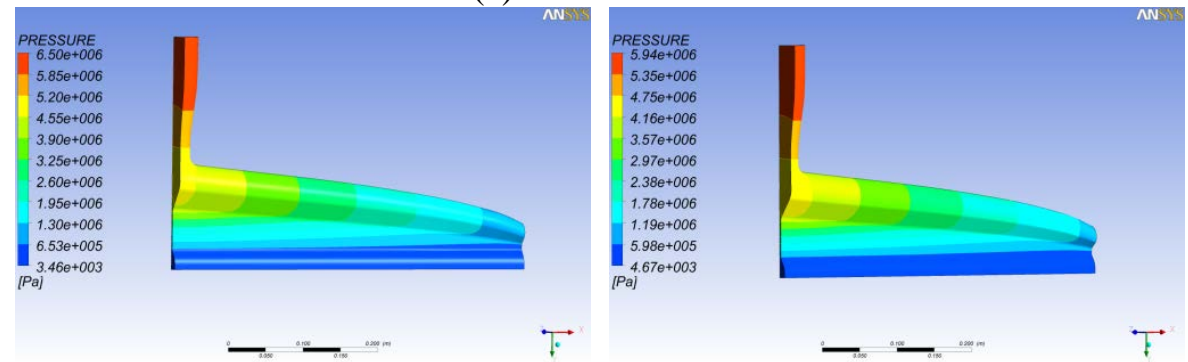

(d) radius increased by $3 \mathrm{~mm}$, $\mathrm{H}$ increased to $6 \mathrm{~mm}$ (e) radius increased by $5 \mathrm{~mm}, \mathrm{H}$ increased to $6 \mathrm{~mm}$

Fig. 11 The pressure drop of the coat hanger die after improvements

At $225^{\circ} \mathrm{C}$,the pressure drop of the original die is $9.44 \mathrm{Mpa}$. After $3 \mathrm{~mm}$ increment of the entrance pipe and the manifold radius, the pressure drop decreases to $8.18 \mathrm{Mpa}$ reducing by $1.26 \mathrm{Mpa}$. When the radius of the entrance pipe and the manifold was increased by $5 \mathrm{~mm}$, the pressure drop decreases to 7.61Mpa. When the inlet pipe and manifold radius increases to a certain extent, the effect of the increase of the radius on the pressure drop is not obvious.

Table 2 Summary of pressure drop

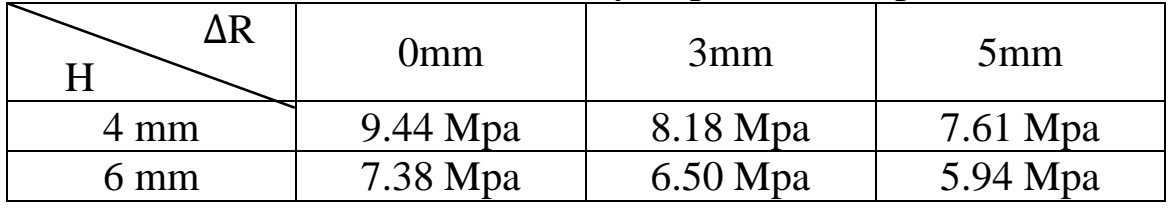

After the thickness of the sector increasing to $6 \mathrm{~mm}$, the pressure drop decreases to $7.38 \mathrm{Mpa}$ reducing by $2.06 \mathrm{Mpa}$. On this basis, when the inlet pipe and manifold radius was increased the pressure drop is further reduced, but not obvious (Table 2).

\section{Conclusion}

At $225^{\circ} \mathrm{C}$, the excessive pressure drop of the die and distributor is the main reason for the failure of the coat-hanger die. And the poor uniformity of velocity distribution at the exit will seriously affect the quality of extrusion products.

The increment of the radius of entrance manifold can reduce the pressure drop of the die, and make the velocity distribution at the exit more uniform. However, when the radius increases to a certain extent, the reduction of the pressure drop will become little. The increase of the thickness of the sector can significantly reduce the pressure drop and makes the velocity distribution at the exit more uneven. 


\section{References}

[1] Wang Xinhou. Study on the design theory of coat hanger die [J]. Journal of China Textile University, 2000,26 (1): 111-115.DOI:10.3969/j.issn.1671-0444.2000.01.026.

[2] J.F.Carley. Flow of Melts in Crosshead-Slit Dies. Criteria for Die Design [J]. Appl. Phys. 1954, 25, 1118.

[3] Ito K. Flow of melts in flat die. II Coat-hanger die [J] .High Polym Chem. 1963:20-201.

[4] Matsubara Y. Residence time distribution of polymer melts in the linearly tapered coat-hanger die [J]. Polym Eng Sci. 1983,23:17

[5] Gong xuan, Wu Hongwu. The design theory of hanger die and its numerical simulation [J]. Plastic,2010,39(2):1-3,64.

[6] Wang Hehui, Zhu Wenmin, Lu Pangu, Si Yuanxiang. Design and numerical verification of the coat hanger die with inlet radius as the parameter [J]. Plastic,2016,02:101-105.

[7] Li He, Xiang Huiyu, Xue et al. Analysis of the influence of the geometric size of the flow path on the flow rate of the racks [J]. Electronic world,2015,(19):36-38.

[8] Wang Jian, Tao Ruitao, et al., et al.,. Effects of slip and process conditions on the extrusion process of ABS rod by numerical simulation [C].// Proceedings of the Eleventh Annual National Symposium on Chemical Technology.2011:226-229.

[9] Qin Shengxue, Chen Haiming, etc.. Finite element simulation of UHMWPE single screw extrusion under wall slip condition [J]. Computer aided technology, 2014,42(6):85-88. 